\title{
Organizational study of a large U.S. Non-profit: A Diagnosis of Organizational and Leadership Issues
}

\author{
Saumya Pradhan \\ School of Business and Public Administration, University of the District of Columbia, USA \\ saumya.pradhan@udc.edu \\ Sergey Ivanov, Ph.D. \\ School of Business and Public Administration, University of the District of Columbia, USA \\ sivanov@udc.edu
}

\begin{abstract}
Organizations that are sick with organizational diseases make cutbacks in size and spending, which mostly impact the workforce with massive layoffs. Employees in these organizations are unhappy, frustrated, and live in constant fear of losing their jobs. Employees are doing "pseudo work" (Ivanov, 2017) verses "real work," pushing the organization into a vicious cycle of more cutbacks and layoffs. This paper discusses organizational diseases, such as double talk, double think, Abilene Paradox, lack of collaboration, lack of innovation, focus on performance evaluations, and examines whether they exist in the company, a large nonprofit organization in the US. The authors then suggest recommendations for improvement to upper management.
\end{abstract}

Key Words: Pseudo Work, Double Talk, Double Think, Abilene Paradox, Collaboration, Innovation, Management Diseases, Deming

\section{Introduction \\ In Sickness and in Health}

Many American organizations are in crises today because of the leadership diseases that plague them. The focus on short term goals and quotas (Deming, 1992, 1993, 1994), and their neglect of the front line and the need to constantly innovate has hindered growth, which ultimately has led to many organizations' collapse.

Organizations that are sick with diseases have had to make cutbacks in size and spending, punishing mostly the workforce with massive layoffs. Employees in these organizations are unhappy, frustrated and live in constant fear of losing their jobs. Employees in these organizations are doing "pseudo work" verses "real work" (Ivanov, 2017) - which pushes the organization into a vicious cycle of more cutbacks and layoffs. The fate of the organization lies in the hands of upper management (Deming, 1992,

The current issue and full text archive of this journal is available

http://jraspublications.org/index.php/JRAS/issue/archive

Journal of Research in Administrative Sciences (JRAS)

VI(I), 1-6, ISSN: 2664-2433
1993, 1994). It is their responsibility to guide the organization in the right direction and to ensure good health and longevity. For the organization to do well, the upper management, middle management, and front line need to work as a system. Since, the frontline is the lowest tier of the organization that performs the work, and is the face that customers interact with, it is important that the front line is not afflicted with problems such as job insecurity, unnecessary job stress, frustration, and mistrust of management and colleagues. People should have the means to perform well on the job, feel secure, appreciated, and satisfied so they are doing real work in the organization. The upper management relies on the middle management to ensure that the needs of the front line are met, ensuring the organizational system is functioning. Therefore, upper management should design and 
Organizational study of a large U.S. Non-profit: A Diagnosis of Organizational and Leadership Issues S. Pradhan, S. Ivanov, Ph.D.
Academy of Contemporary Research Journal

Volume VI, Issue I, 2017, 1-6 implement a system that motivates and encourages everyone to work well, the middle management helping frontline, fostering communication, collaboration, creativity and innovation at every level of the organization.

Common symptoms of a sick organization are the prevalence of double talk, double think, lack of collaboration, lack of communication, and quantitative metrics of performance. This paper examines whether such symptoms exist in The Company, and determines if the organization is sick; and if it is, makes recommendations to upper management to help the organization recover.

The Organization is one of many international nonprofit organizations headquartered in the United States. It is a fairly large company with an annual revenue of about USD 150 million. Its programs are implemented around the world through satellite offices called "field" offices, and the financial accounting and reporting for the dollars spent oversees are completed by the Accounting team at the US Headquarters. The headquarters has a rather complex structure with separate departments for different functions such as Operations, Human Resources, Information Technology, and Accounting. The Accounting Department, by itself, has about fifty people and is divided into sub-teams: Project Accounting, Subgrant Accounting, and Financial Planning and Analysis (FP\&A). The analyses in this paper focuses on observations of the Accounting sub-teams as it relates to the theories of organizations, as identified by Deming (1992, 1993, 1994), Harvey (1988, 1999), Jaques $(1996,2002)$, and Ivanov $(2011,2012,2013,2014,2015,2017)$.

\section{The Organizational System}

The Project Accounting team consists of three subteams: Project Accounting, Subgrant Accounting, and Financial Planning and Analysis. The Project Accounting team works with field offices, reviews their financial reports, and captures field data into the primary accounting software in the US headquarters. The Subgrant team works with subgrantee organizations that receive grants from the organization. The team reviews and transfers financial data into the primary software. FP\&A reviews and analyzes budgetary information, and manages financial reporting. Each sub-team has a manager and about fifteen team members lead by the Director of Accounting, the Controller, and the Chief Financial Officer.

For the Accounting team, we can identify the Chief Financial Officer, the Director of Accounting and the Controller as the upper management, the managers of each of the sub-teams as middle management, and the members of the Project Accounting team as the front line. Since the Project Accounting team processes financial information for the Program, teams and donors, customers for the Accounting team can be identified as the program teams, the donors whose funds the organization manages, and ultimately the beneficiaries who are impacted by the programs. In most other non-profit organizations of similar size, Project Accounting, Subgrant Accounting, and FP\&A are managed by one team. For example, one person may be overseeing anywhere from 30-60 smaller projects, whereas in other organizations, one person would work on 3-6 projects, but they oversee all aspects of the project related to the projects' finances.

The benefit of having such a unique structure is that the three sub-teams are specialized in their own area of focus. Staff members in each of the teams have worked in the organization for eight to thirty years, and there is a strong sense of comradery within the smaller teams. It is hard to find organizations today where people have chosen to stay for so many years. The sense of community is strong within each of the sub-teams. However, there are organizational diseases that are prevalent in the organization.

\section{Symptoms of a Sick Organization Double Talk}

Work is the essence of a human being (Ivanov, 2017). Everything that a human being does is work survival, reproduction, or nursing of a child (Ivanov, 2017). Like any relationship, work is built on trust that has been gained over a long period. When people find out that the exchange of information in the relationship is not truthful, people lose trust, causing the relationship to end (Ivanov, 2017).

Double talk is a form of lying that commonly exists in an organization. Double talk is malicious lying and intentionally ambiguous speech to hide the truth and manipulate the listener. When employees recognize that double talk exists in the relationship with their manager, colleagues, or the upper management, employees lose trust in the relationship. They feel betrayed, disappointed, sad, angry, frustrated and depressed. This results in pseudo work (Ivanov, 2017), unhappy workforce, high employee turnover and inefficiencies that keep the organization from working as a system - ultimately leading to the downfall of the organization.

Double talk is present in the organization. There are many occasions where managers and colleagues have stated one thing and only a few days later changed their statements. For example, a manager encouraged employees mingle with co-workers, and find a good work life balance. However, the same manager, on many occasions, mentions that work is best done after hours when everyone has left, encouraging employees to stay longer than the usual 8-hour work day. It is especially disappointing hearing supervisors asking to stay late when employees have already spent several nights working until $9 \mathrm{pm}$ or later in the evenings. These are all obvious contradictions to having a good work life balance or being social at work.

\section{Phrog Farm}


Organizational study of a large U.S. Non-profit: A Diagnosis of Organizational and Leadership Issues S. Pradhan, S. Ivanov, Ph.D.
Academy of Contemporary Research Journal

Volume VI, Issue I, 2017, 1-6
The article by Harvey, Organizations as Phrog Farms, double think I prevalent in many organizations (1988). Employees in these organizations are encouraged, or even forced to conform to the crowd. They can only speak the language of "Ribbit" in the organization, and speaking any other language or implementing a new idea is viewed as disturbance in the organization.

Because things have been done a certain way, they must follow suit regardless of whether the employees agree or disagree. New employees who join the organization are also told that it is the only way of doing things; no creativity is allowed, and no new ideas of improvement or innovation are welcomed. Employees in these organizations are afraid to speak up about change or new ideas because they don't want to be viewed as the spoiler who disturbs the ecology of the organization. They are afraid of becoming the outlier, and of being separated from the rest of the company; and in the worst case, they are afraid of being fired because they were "not powerful enough" to disagree.

The organization's work environment resembles the work environment described by Harvey. The business environment is not welcoming of change. The common phrases are "we have been doing this for years, and it works. This is how we do things at this company."

\section{The Abilene Paradox}

The Abilene Paradox, as Harvey describes (1988), is a paradox in which the group agrees with a course of action that is contrary to every member's wish. When the action leads to a negative outcome, members of the group confess that they initially disagreed with the decision, and blame the others in the group for the mishap.

The Abilene Paradox occurs because individuals hesitate to speak up about their honest view to avoid upsetting, or disturbing the farce consensus, and because individuals fear that their opinion could make them the "odd one out" in the group. This occurs in work settings, and even among friends or family (Harvey, 1988).

In a work scenario, people hesitate to share their thoughts among their colleagues or superiors because of fear of being viewed as a non-team player. Their opinion may also be viewed as negative criticism of what is unanimously accepted as the norm, potentially causing losing their job.

The organizations experiences Abilene often. For example, when reviewing a document that was on its way to the donor, an employee noticed a discrepancy that would have lost the organization a good amount of revenue and reputation. Relaying the error to the program team member, John Doe, who prepared the document, John did not want to change it because of time constraints, and because his supervisor had already signed off on it.
Explaining the consequences of submitting the document as is, and that we have the choice of asking some additional time from the donor to correct the error would have been a good course of action. When after several attempts, John successfully convinced him to sign off on the erred document.

The Contracts department agreed and the budget was submitted as is. A few weeks later, we found out from the donor that they were not happy with our submission resulting in a loss of revenue. The program team and contracts team blamed the accounting team, and the accounting team blamed the program team for the loss.

\section{Lack of Collaboration}

Harvey (1988) describes "cheating" as an act of giving and receiving aid. Because how "cheating" has been viewed as a behavior that is immoral and taboo, it seems that people are discouraged to help others, or ask for help themselves. Thus, they are discouraged to collaborate with others.

I believe that the organization suffers from the disease of lack of collaboration, or Deming's (1992, 1993, 1994) way of "cheating." The sub-teams work as separate teams rather than one. There is little collaboration, and flow of information amongst the sub-teams. Each team being led by different managers seems to act as a separate organization that holds information amongst itself only.

Although the team three sub-teams work on the same projects, they do not have access to the financial information that the other teams work on, as each team has different levels of access to the financial system. For example, if a person from FP\&A team needs information regarding subgrants on their projects, s/he must ask the subgrant team for the information. The subgrant team will then log on to the system and hand over a printout of the information. In most other organizations, the information is readily available in a central repository, but at this organization, the accounting teams seem to be guarding their "specializations."

Because the accounting team performs smaller number of tasks for many projects at time, they are not able to dive into details or understand the project comprehensively. It almost feels like an assembly line in a mass production factory where each person is responsible for a small task, and that he is repeatedly performing the same task without having to think much about what he or she is doing, or how $\mathrm{s} /$ he is contributing and impacting the bigger picture. The lack of collaboration exists even between the sub team and their manager, where the manager is holding on to certain tasks that could easily and more efficiently be completed by the junior team members. Most of the team members have been doing the same

tasks for 8 to 10 years and have expressed the boredom and lack of challenge with their work; they 
Organizational study of a large U.S. Non-profit:

A Diagnosis of Organizational and Leadership Issues

S. Pradhan, S. Ivanov, Ph.D.

have also conveyed that they sometimes "feel stupid" that their manager avoids passing tasks to them.

\section{Lack of Innovation}

An organization must constantly innovate and create new products to stay in business (Deming, 1992, 1993, 1994). Regardless of how well it is doing today, it should think of where it needs to be in the long run and constantly improve and innovate its products and services to maintain its customer base, and to stay in business. Without innovation, the organization will lose customers to others who have innovated, or through attrition (Deming, 1992, 1993, 1994), (Ivanov, 2011, 2012, 2013, 2014, 2015, 2017).

The present organization environment is not welcoming of change. When attempting to suggest a new way, the basic response is "we have been doing this for years, and it works. This is how we do things at this company." The organization suffers from this disease. Processes, business systems and technology are also outdated. Similar/competing non-profit companies already upgraded their processes a decade ago. The systems at the organization are at least one decade behind.

Deming writes (1992, 1993, 1994), "competent men, doing their best on their jobs, know all that there is to know about their work except how to improve it. Knowledge necessary for improvement comes from outside." Possibly, because the team members have been working with the same processes for a long time, they have not yet explored ways to innovate their processes for more efficient ones, and overall improving the system. They seem too comfortable with their ways and backbite employees who ask too many questions and try to understand "why" instead of just using the "template."

For example, companies today can access real time financial information of their field offices. The organization's business systems get the field financial data almost two months late. The software technology is also slow, with reports that are not userfriendly and do not allow customizing. Data that should take seconds to retrieve takes minutes to extract, and further requiring heavy formatting before it can be used. Surely, the systems work, but competitors (other non-profit organizations) have outperformed these processes years ago, and they can produce the same work faster, more accurately, based on newer regulations, and for less money. Competitors that can deliver programs more efficiently, and can provide financial oversight and accountability that looks more appealing to donors. This is a threat to the organization's future: its ability to win future projects.

The organization has not looked at improving their processes and systems for years, let alone innovated them for cutting edge financial management for efficient and effective programming.

Performance Evaluations
Deming $(1992,1993,1994)$ argues that a focus on performance evaluations is an organizational disease. Deming calculates that $96 \%$ of the employee performance depends on upper management. Evaluating and grading performance of employees does not benefit anyone. Ranking employees based on a numerical scale does not lead to better performance, but instead it only leads to pseudo work (Ivanov, 2017) where employees are only focusing on getting the job done, and fulfilling the requirements of the job.

The organization has a performance evaluation system that the Human Resource department recommends. The team members evaluate themselves every year, and then turn it in to the team manager for feedback, continuing this wasteful practice.

\section{Conclusion and Recommendations to Upper Management}

Based on the observations above, the organization suffers from the diseases, and therefore, it should seek ways to remedy its health. Below are recommendations for upper management.

It is the responsibility of upper management to take all measures to restore the organization (Deming, 1992, 1993, 1994).

The upper management, middle management, and front line need to work as a system and they should eliminate barriers, rankings, and the "sense of seniority" in the organization. Performance of an employee depends on management. Instead of wasting time on grading employees' work, the focus should be on improving the system.

Upper management and middle management should ensure that they are providing the right support, training, and encouragement to the front line, and channel the intuitive skills and abilities of employees to improve their skills and performance which will in return, add value to the organization.

Upper management should create and foster an environment for creativity and innovation, as well as improvement. They should encourage employees to speak up; and they should listen, and support implementing innovative ideas. There should be work environment that encourages employees to think, improve, and innovative.

It is also important that organization's teams work together. All sub-teams should be treated the same and should have equal access to financial and other information. It is understandable that some financial information is sensitive, and should not be openly available, but allowing teams to at least use some of the reporting templates would help them retrieve the information on their projects more easily. They would also be learning about other financial aspects of their projects, and expanding their knowledge, instead of performing only cookie cutter tasks. Seeing all aspects of their projects, the teams would be able 
Organizational study of a large U.S. Non-profit:

A Diagnosis of Organizational and Leadership Issues

S. Pradhan, S. Ivanov, Ph.D.
Academy of Contemporary Research Journal

Volume VI, Issue I, 2017, 1-6 to understand their own work better, possibly feeling responsible for the full picture rather than only their part. This would allow teams to not feel compartmentalized, and may improve collaboration amongst various business teams.

Regular monthly meetings among the teams may also increase the interactions, exchange of ideas, and knowledge of what the other teams do and the challenges they face. This should help the teams understand the whole project, see the bigger picture, and the common goal rather than just being a number on an assembly line. This would also help the team exchange information more freely, and not feel that they are sharing their team information with "outsiders."

The meetings could be informal and open. This would allow teams get to know each other and be comfortable with each other.

The meetings should also be a forum where upper management gets to interact with everyone and could openly talk about ongoing news in the organization. Upper management should ask team members about issues and ideas. This would also allow people to feel comfortable to talk to upper management, and feel that they can speak about their ideas and opinions, and not feel afraid to change the current systems for change and innovation.

Upper management, team members, and managers should attend these meetings to speak with each other. Leaders need to show interest in the work of their employees and encourage ideas for innovation. They should also encourage their teams to speak up at meetings with other teams, so that each member feel important and contributing.

Leaders should be open enough to share work with the front line to keep them motivated, and collaboratively brainstorm on what the organization's future plans are. These efforts would make employees feel an integral part of the organization.

\section{References}

i. Deming, W. Edwards (1993). The New Economics: For Industry, Government, and Education. Cambridge, MA: Massachusetts Institute of Technology.

ii. Deming, W. Edwards (1994). The New Economics: for industry, government, education. Cambridge, MA: MIT/CAES Press.

iii. Deming, W. Edwards (1992). Out of the Crisis. Cambridge, MA: Massachusetts Institute of Technology.

iv. Harvey, Jerry B. (1988). The Abilene Paradox and Other Meditations on Management. CA: Lexington Books.

v. Harvey, Jerry B. (1999). How Come Every Time I Get Stabbed in the Back, My Fingerprints Are on the Knife?. San Francisco, CA: Jossey-Bass.

vi. Ivanov, Sergey (2011). Why Organizations Fail: A Conversation About American
Competitiveness. International Journal of Organizational Innovation, 4(1), 94-110.

vii. Ivanov, Sergey (2013). Defects in Modern Organizations: Field Findings and Discovery. International Journal of Innovation, Management and Technology, 4(2), 204-208.

viii. Ivanov, Sergey (2012). The Problem of Defects in Modern Organizations: Preliminary Research Findings. International Proceedings of Economics Development and Research: Management and Education Innovation, 37(1), 42-45.

ix. Ivanov, Sergey (2014). Organizational Studies. www.SergeyIvanov.org: Unpublished Manuscripts.

x. Ivanov, Sergey (2014). Feararchy and Organizations. Melbourne, Australia: Swinburne University of Technology.

xi. Ivanov, Sergey (2015). Exposing Myths of Modern Management: Innovation - Identifying the Problem. Journal of Leadership and Management, 1(3), 57-66.

xii. Ivanov, Sergey (2015). Exposing Myths of Modern Management: Innovation - Exploring a Solution. Journal of Leadership and Management, 2(4), 29-34.

xiii. Ivanov, Sergey (2015). The Work of Associations: A Hidden Dimension of All Managerial Hierarchies (Bureaucracies). Journal of Leadership and Management, 2(4), 41-45.

xiv. Ivanov, Sergey (2013). Defects in Modern Organizations: Field Findings and Discovery. International Journal of Innovation, Management and Technology, 4(2), 204-208.

xv. Ivanov, Sergey (2011). U.S. Analyst Predicts a Nationwide Russian Crisis in 2035-2040: It Is Not the U.S. but Russia that May Collapse... Again!. International Journal of Humanities and Social Science, 1(15), 215-216.

xvi. Ivanov, Sergey (2013). Leaderless Organizations: Why Our Organizations Continue to Fail. 2013 International Business Conference Proceedings: Society for Advancement of Management.

xvii. Ivanov, Sergey (2002). Recommendations for the Practical Use of Elliott Jaques' Organizational and Social Theories in the Information Technology Field: Teams, Software, Databases, Telecommunications and Innovations.

xviii. Ivanov, Sergey (2017). Exposing Myths of Modern Management: The Difference between Work and Pseudo-Work or Why Modern Organizations Don't Do Any Work. Work-inprogress, 1(1), 1-10.

xix. Ivanov, Sergey (2017). Why Organizations Fail: Organizational Studies Based on Theories of Dr. Elliott Jaques . Kindle: Amazon Digital Services LLC.

xx. Jaques, Elliott (1989). Requisite Organization: The CEO's Guide to Creative Structure and 
Organizational study of a large U.S. Non-profit:

A Diagnosis of Organizational and Leadership Issues

S. Pradhan, S. Ivanov, Ph.D.
Academy of Contemporary Research Journal

Volume VI, Issue I, 2017, 1-6

Leadership. Arlington, Virginia: Cason Hall and Co..

xxi. Jaques, Elliott (1976). A General Theory of Bureaucracy. London, UK: Heinemann Educational Books.

xxii. Jaques, Elliott \& Cason, Kathryn (1994). Human Capability. Rockville, MD: Cason Hall.

xxiii. Jaques, Elliott \& Clement, Stephen D. (1991). Executive Leadership: A Practical Guide to Managing Complexity. Falls Church, VA: Cason Hall \& Co. Publishing Ltd.

xxiv. Jaques, Elliott, Gibson, R. O. \& Isaac, D. J. (1978). Levels of Abstraction in Logic and Human Action: a theory of discontinuity in the structure of mathematical logic, psychological behaviour, and social organization. London, U.K.: Heinemann Educational Books.

xxv. Lewin, Kurt (1945). Resolving Social Conflicts: Selected Paper on Group Dynamics. New York, NY: Harper \& Brothers.

xxvi. Sharansky, Natan (1998). Fear No Evil. New York, NY: PublicAffairs.

xxvii. Toffler, Alvin (1970). Future Shock. New York, NY: Random House.

xxviii. Weber, Max (1983). On Capitalism, Bureaucracy, and Religion: A Selection of Texts.

xxix. Wilkinson, Richard G. (1996). Unhealthy Societies: The Afflictions of Inequality. New York, NY: Routledge 